${ }^{2}$ Ledingham, J G G, and Rajagopalam, B, Quarterly fournal of Medicine. In press.

${ }^{3}$ Eagling, E M, Sanders, M D, and Miller, S J H, British fournal of Ophthalmology, 1974, 58, 990.

${ }^{4}$ Hayreh, S S, British fournal of Ophthalmology, 1969, 53, 721.

(Accepted 2 April 1979)

Dudley Road Hospital, Birmingham B18 7QH

D H COVE, BSC, MRCP, senior registrar

$M$ SEDDON, MB, CHB, senior house officer

R F FLETCHER, MD, FRCP, consultant physician

Coventry and Warwickshire Hospital, Coventry

D C DUKES, MD, MRCP, consultant physician

\section{Cervical carcinoma-in-situ in woman exposed to diethylstilboestrol in utero}

Exposure to diethylstilboestrol (DES) in utero was shown eight years ago to be associated with vaginal adenocarcinoma ${ }^{1}$; since then over 300 cases have been reported. The major risk from such DES exposure, however, may not be the development of a clear-cell adenocarcinoma but of vaginal and cervical squamous neoplasia. ${ }^{2}$ The prevalence of dysplasia in such cases is reportedly $2.1 \%,^{3}$ whereas there is an estimated fivefold increase in the incidence of carcinoma-in-situ. ${ }^{4}$ Thus there is the possibility of a vast increase in squamous malignancy as a result. The following case is apparently the first to be recorded in Great Britain of carcinoma-in-situ in a DES-exposed patient.

\section{Case report}

The patient, an unmarried woman, had been exposed to increasing doses of DES from six to 36 weeks of gestation because of a maternal history of recurrent abortion. The total dose was unknown. When she was aged 23 colposcopy showed extensive adenosis of the cervix extending on to the vaginal vault. Four years later she presented for further investigation at the Chelsea Hospital. She was nulliparous and taking oral contraceptives.

Colposcopy showed a cockscomb on the anterior lip of the cervix with pronounced punctation and aceto-white epithelium (cervical intraepithelia neoplasia grade III) in a wide transformation zone. Metaplastic changes extended on to both fornices in areas of adenosis: cytology showed dyskaryotic and malignant squames, class IV. A cone biopsy specimen was taken from the cervix, pathological examination of which showed a small os and rough nodular surface epithelium. Microscopy disclosed a squamocolumnar junction and distal immature squamous epithelium overlying endocervical glands corresponding to the area of colposcopic adenosis. Varying lengths of this squamous epithelium were severely dysplastic with changes of carcinoma-in-situ in some glands. There was no evidence of invasive carcinoma, but in two blocks the abnormal epithelium extended to the outer, resected margin.

Subsequent management included admission for cervical dilatation because of stenosis. The remaining areas of moderate dysplasia on the cervix and vaginal fornices were locally destroyed with a carbon dioxide laser. Continuing colposcopic and cytological surveillance showed no abnormality.

\section{Comment}

This case illustrates the risk of cervical intraepithelial neoplasia developing in association with adenosis, itself the result of exposure to DES in utero. We recommend that clear-cell adenocarcinoma of the vagina should be sought by careful clinical, cytological, or colposcopic observation from the menarche or age 14 onwards, whichever is the earlier. Yearly examinations or occasionally more frequent ones have been recommended. It is clearly also necessary to look for areas of abnormal metaplasia in the much-enlarged transformation zone found in these cases. Abnormal areas should be biopsied and subjected to careful histological examination. Should carcinoma-in-situ be detected precise local eradication is needed.

Ultimately invasive carcinoma may develop in some-perhaps many -of these patients, and the greatest care in follow-up will be required.

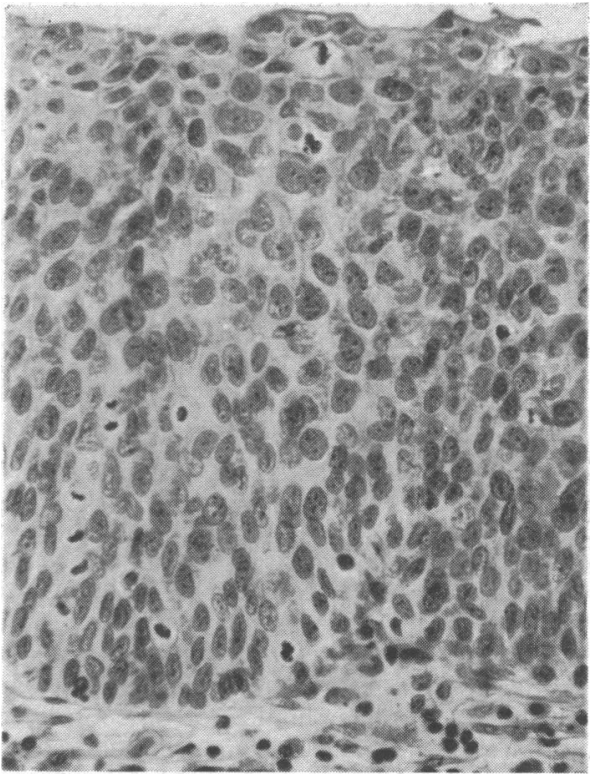

High-power photomicrograph of cone biopsy specimen from cervix showing carcinoma-insitu. $\times 25$ objective (original magnification).

Although satisfactory healing of the areas of adenosis may occur by squamous metaplasia within a year of onset, colposcopic changes may persist for longer. ${ }^{5}$ Despite this degree of reassurance clearly great vigilance will be needed for some years before the risks can properly be evaluated.

${ }^{1}$ Herbst, A L, Ulfelder, H, and Poskanzer, D C, New England fournal of Medicine, 1971, 284, 878.

${ }^{2}$ Staf, A, and Mattingly, R F, American fournal of Obstetrics and Gynecology, 1974, 120, 666

${ }^{3}$ Bibbo, M, et al, Obstetrics and Gynecology, 1977, 49, 1.

${ }^{4}$ Mattingly, R F, and Stafl, A, American fournal of Obstetrics and Gynecology, 1976, 126, 543.

${ }^{5}$ Emens, J M, Allen, J M, and Jordon, J A, in Abstracts of the 1978 III World Congress for Cervical Pathology and Colposcopy. In press.

(Accepted 12 June 1979)

Institute of Obstetrics and Gynaecology, Queen Charlotte's Hospital for Women, London W6 OXG

JOHN H SHEPHERD, FRCS, MRCOG, lecturer and honorary senior registrar (present appointment: cancer fellow, Department of Gynaecological Oncology, University of South Florida, Tampa, Florida 33612, USA)

SIR JOHN DEWHURST, FRCSED, FRCOG, professor

J PRYSE-DAVIES, MD, FRCPATH, honorary senior lecturer

ONE HUNDRED YEARS AGO A trial for homicide has recently taken place at Avallon in France, in consequence of the poisoning of a patient by mistake. M R, a pharmacien at Avallon, sold to Dr L, a medical practitioner in the same town, a quantity of false angustura bark instead of pomegranate root. Dr L, misled by a certain degree of resemblance between the two substances, and believing that he was using pomegranate root, made an infusion of the substance and gave it to a patient, who died in consequence of taking it. An action for homicide by imprudence was brought against the pharmacien and the doctor. The tribunal at Avallon and the Court of Appeal in Paris decided that both were guilty. They refused to admit the plea that Dr L might have been misled by the similarity of the two substances, alleging that he ought to have noticed that the infusion which he prepared had not the ordinary appearance of infusion of pomegranate bark, and emitted an unusual odour; and that his suspicion ought to have been excited by the symptoms produced in another patient to whom he had given the same medicine a few days previously. The local tribunal fined M R two hundred francs, and Dr L twenty-five francs. The Court of Appeal added to the fine on the pharmacien a sentence of imprisonment for fifteen days, and increased Dr L's punishment to a fine of two hundred francs. (British Medical fournal, 1879.) 